\title{
Pattern of bear maul injuries in tertiary hospital in nepal: demographic, management and outcome
}

\author{
Rayamajhi S ${ }^{1}$, KC K², Shrestha JM1', Lohani I ${ }^{1}$ \\ ${ }^{1}$ Plastic and Reconstructive Unit, Department of Surgery \\ ${ }^{2}$ Oral and Maxillofacial Surgery Unit, Department of Dental Surgery
}

Correspondence: Dr Sangam Rayamajhi, TUTH, Maharajgunj, Nepal,

Email: sangamrayamajhi@gmail.com

\begin{abstract}
Introduction: Nepal is a country full of forests and with increase in urbanization there is encroachment into the territories of wild animals. Their encounters have been in the rise and bear maul seem to be one of the leading cause of wild animal attacks. The injuries are very disastrous and leave behind permanent disfigurements and disabilities.

Methods: All of cases of bear maul treated in TU Teaching Hospital for the last 6 year were studied. Analysis of pattern and severity of the injuries were done along with the complication and its morbidities.

Results: Total of 17 cases was studied. Majority of the cases were male and at age of 20 to 40 years. All but one were sudden attack by Himalayan black bear (15 cases) using their claws (in 17 cases) mostly to the face (16 cases), eyes (10 cases) and scalp ( 8 cases) resulting in fractures (14 cases). There were more proportion of patient with the complex wounds (10 cases) requiring initial debridement followed by closure with graft ( 5 cases), flap ( 5 cases) or free flaps ( 1 case) than the simple wounds which were just debridement and closed with primary ( 5 cases) or secondary sutures ( 2 cases). All patients were left with ugly scar and majority had facial disfigurements (12 cases) with major contour deformities ( 7 cases). Four patients had permanent vision loss in one eye.

Conclusion: The rising trend of bear maul injuries, are complex injuries requiring prompt multidisciplinary approach of management. Face and eyes are the most common sites of injuries and often associated with underlying fractures. Bear maul though rarely fatal, leaves permanent disfigurement and disabilities.
\end{abstract}

Keywords: Bear attacks; facial injuries; South Asia; reconstructive surgery

\section{Introduction}

Nepal is a country of mountains, hills and plains covered with forests and snow inhabitant by various wild animals. With the encroachment of human colonies into the forest areas, there have been several encounters between the human and the wild animals, and often the results are grievous.

A survey conducted by the Annapurna Conservation Area Project (ACAP) in 2013 reports a significant increase in the tendency of Asian black bear entering human settlements, damaging crops and attacking humans in Annapurna Conservation Area. ${ }^{1}$ The study has shown an increase in the incident of bear attacks, raising questions about security of local residents in the area. Bears are found to disfigure the faces of the victims in frontal attacks.

A bear maul is an attack by any mammal of the Ursidae family. Asian black bear (Ursus thibetanus), Sloth bear Melursus ursinus) and the Himalayan brown bear (Ursus arctos isabellinus) are the species commonly found Nepal. 
Bear aren't very aggressive animal when left alone but they do attack humans when they are surprised or provoked with threat to themselves or their young ones or when they are hungry. ${ }^{2}$

Bear use their arms more than their jaws to attack their victims. Their heavy arm can produce heavy blows with power up to 100 Newton. Injuries vary from small abrasion to devastating and fatal injuries. Brigadier General R. G. Burton has very nicely described; "the Himalayan black bear is a savage animal, sometimes attacking without provocation, and inflicting horrible wounds, attacking generally the head and face with their claws, while using their teeth also on a prostrate victim. It is not uncommon to see men who have been terribly mutilated; some having the scalp torn from the head, and many have been killed by these bears." 3

Bear encounters are categorized as sudden, provoked or predatory. In sudden encounters, neither the person nor the bear is aware of each other's presence till they are in close range of each other. Such encounters are usually defensive in nature whereby the bears try to protect their young ones, their food cache or their territory. Provoked encounters are the second most common type of encounters. Such cases occur with bear hunters and wild life photographers. Hunters who either miss or place an inadequate shot can become a victim of their prey. Predatory attacks are defined as the ones where the bear clearly treats its victim as a food source. $^{4}$

Reports regarding the pattern of injuries caused by bears in humans are scarce in literature, though much has been written on bears, their attacks with various case reports and methods of prevention from such attacks. This study is conducted to assess and describe pattern and severity of the injuries sustained due to bear maul and to emphasize the permanent damage they cause.

\section{Methods}

This is a descriptive study with analysis of all the cases of bear maul injuries in the last 6years. All these cases were managed in Plastic and Reconstructive Surgery Unit, Department of Surgery of tertiary health care center (TUTH) with multi-disciplinary coordination. Data were collected retrospectively from April 2009 to November 2011 and prospective since then; a detailed history was recorded including patient demographics, date and place of attack, type of bear (if known), time from attack to hospital arrival, circumstances leading to the attack. All examination findings were recorded. Patient were followed through their stay in hospital and pertinent data were recorded like; type and severity of injury, types and number of operations, length of hospital stay and complications.

\section{Treatment protocol}

Patients were received in Emergency Room (ER) in TUTH, primary survey was done and life threatening conditions were managed. Secondary survey was done meticulously to evaluate the presence of any associate injuries. Wounds were thoroughly examined and details were all recorded along with photographs. All needed specialties consults were done in ER followed by needful investigations.

Anti-rabies vaccinations were started according to the WHO regimen. We followed five dose intramuscular regimens, that is, one dose of vaccine administered on days $0,3,7,14$ and 28 in the deltoid region (or in antero-lateral thigh muscles small children). Anti-rabies immunoglobulin was given in the dose of $40 \mathrm{IU} / \mathrm{kg}$ body weight of which half was given locally at the site of the wound, and half was given intramuscularly (to whoever could afford it as it is not available for free from the government). A single shot of tetanus toxoid was given in accordance with the immune status of the patient. IV antibiotic was given empirically to all patients in ER and continued post-procedure according to wound swab culture reports.

Wounds were thoroughly washed with normal saline and surgical debridement was done in operating theater. Minor lacerations were closed primarily and complex wounds with gross contaminations were closed as subsequent procedure. Patients were followed in out-patient basis once discharged from hospital and needed surgeries were done if required for deformity correction.

Final statistic analysis of all the recorded data was done.

\section{Results}

Total of 17 cases were treated through the period of six years in our center. Majority (11 out of 17 cases) were of younger age group 20 to 40 yrs of age (Figure 1) with the mean age of $37 \mathrm{yrs}$. Men were found to have more encounter with the bear hence more injured (11 out of 17 cases). Distribution of the encounters was found to be scattered all over the country (Figure 2). Black bear accounted for 13 out of 17 cases of the injuries, rest were by the brown bear. Fifteen out of 17 attacks were due to sudden encounter with the bear surprising them, one was provocative attack of a mother bear and one predatory attack to a shepherd along with a heard of sheep. Only three patients were bitten by the bear where as all were attacked with the claws. 
All cases received their primary case in the primary health center in rural areas and referred to TUTH. Thirteen cases reached our center between the time period of six to 24 hours and all reached by 48 hours (Figure 3). All were stable at receiving in ER. There were no mortalities. Targeted blows to the upper half of the body were found in all cases (Table $1)$; fractures were seen in 10 out of 16 facial injuries and three out of seven upper limb injuries (Table 2). Three out of 10 eye injuries resulted in permanent vision loss and one case of perception of light only. 12 of the patient needed two or more surgeries. Operations included simple suturing of laceration to complex procedures requiring free flap (Table 3). Five out of 13 patients needed flap closure of the wounds out of which one was free flap. Other departments involved in operative and perioperative care were: Emergency Medicine, Oral and Maxillofacial Surgery, Ophthalmology, Orthopedics, Oto-rhinolagryngology and Anesthesiology.

Postoperative complications are enlisted in Table 4. Amongst the permanent consequence, major facial disfigurements were in 12 out of 17 cases, four cases of blindness in one eye, ectropion/ptosis in five cases (Table 5). Mean length of hospital stay was 20days in initial treatment of injuries. Follow up ranged from one to three years.

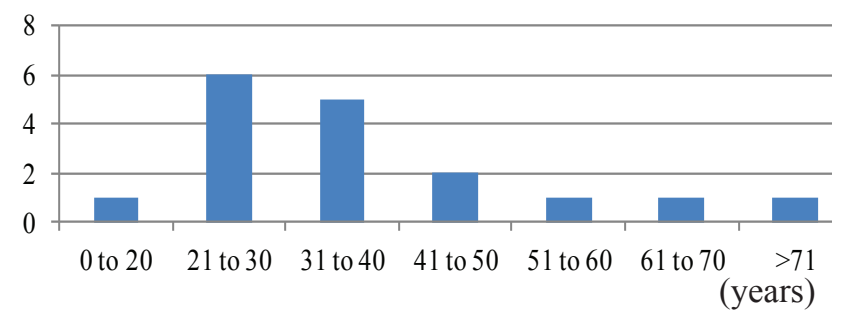

\section{Figure 1: Age distribution}

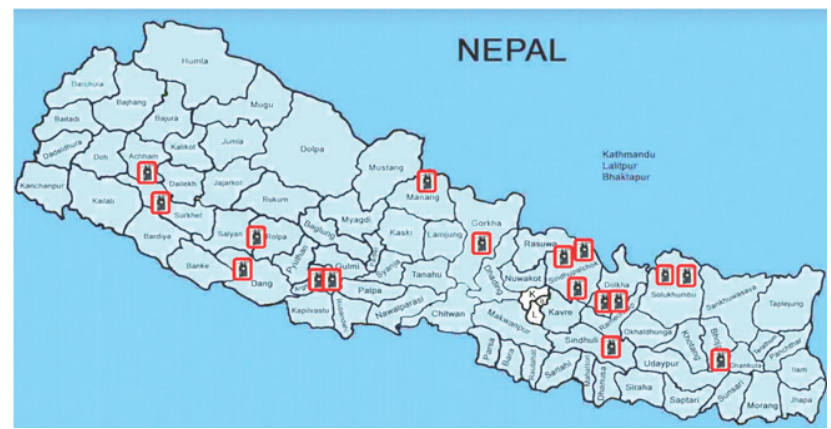

Figure 2: Distribution of encounters

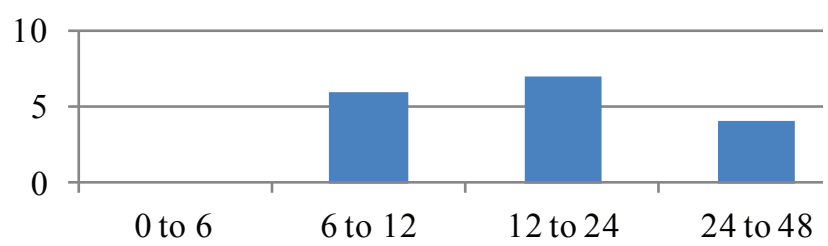

Figure 3: Time of arrival to the hospital

Table 1: Distribution of injuries

\begin{tabular}{lrl} 
Region & \multicolumn{2}{c}{ No of Patients (\%) } \\
Head and Neck & 16 & $(94.1)$ \\
$\quad$ Scalp & 8 & $(47.1)$ \\
Face & 16 & $(94.1)$ \\
Eyes & 10 & $(58.8)$ \\
Chest and abdomen & 4 & $(23.5)$ \\
Upper limbs & 7 & $(41.1)$ \\
Lower limbs & 7 & $(41.1)$
\end{tabular}

Table 2: Sites of fractures

$\begin{array}{lll}\text { Sites } & \text { No of Patients (\%) } \\ \text { Facial fractures } & 10 & (58.8) \\ \quad \text { Skull (Frontal) } & 3 & (17.6) \\ \text { Zygoma } & 4 & (23.5) \\ \text { Nasal } & 3 & (17.6) \\ \text { Orbit } & 7 & (41.1) \\ \text { Maxilla } & 2 & (11.8) \\ \text { Mandible } & 2 & (11.8) \\ & & \\ \text { Upper limbs } & 3 & (17.6) \\ \text { Lower limbs } & 1 & (5.9)\end{array}$


Table 3: Types of operations

\begin{tabular}{lll} 
Operations & \multicolumn{2}{c}{ No of Patients (\%) } \\
Primary Suturing & 5 & $(29.4)$ \\
Secondary Suturing & 2 & $(11.8)$ \\
SSG & 4 & $(23.5)$ \\
Flap closure & 5 & $(29.4)$ \\
Free flap & 1 & $(5.9)$ \\
Fracture fixation & 5 & $(29.4)$ \\
Tracheostomy & 1 & $(5.9)$
\end{tabular}

Table 4: Complications

\begin{tabular}{|c|c|}
\hline Complications & No of Patients (\%) \\
\hline Infection & $2 \quad(11.8)$ \\
\hline Wound dehiscence & $3 \quad(17.6)$ \\
\hline Partial skin graft loss & $1 \quad(5.9)$ \\
\hline Flap necrosis & 0 \\
\hline Ectropion/ptosis & $5 \quad(29.4)$ \\
\hline $\begin{array}{l}\text { Fracture non/mal- } \\
\text { union }\end{array}$ & $2 \quad(11.8)$ \\
\hline Facial nerve palsy & $1 \quad(5.9)$ \\
\hline $\begin{array}{l}\text { Parotid salivary } \\
\text { cutaneous fistula }\end{array}$ & $1 \quad(5.9)$ \\
\hline Meningitis & $1 \quad(5.9)$ \\
\hline
\end{tabular}

Table 5: Outcome

$\begin{array}{lll}\text { Permanent damage } & \text { No of Patients (\%) } \\ \text { Minor Ugly Scar } & 17(100) \\ \text { Facial Deformities } & 12(70.6) \\ \quad \text { Eyelid } & 5 & (29.4) \\ \text { Nose } & 3 & (17.6) \\ \text { Cheek } & 5 & (29.4) \\ \text { Lips } & 2 & (11.8) \\ \text { Alopecia/scalp } & 2 & (11.8) \\ \text { Loss of vision in one eye } & 4 & (23.5) \\ \text { Contour deformity } & 7 & (41.1)\end{array}$

\section{Discussion}

The incidence of bear maul is on a rising trend and the number that we see in this study is just a tip of the iceberg. ${ }^{1}$ There could be unreported mortalities at the site of encounters and majorities of the cases may not have reached tertiary centers due to logistic, geographic and financial limitation of our part of the world. This is depicted by the finding in the study that shows most of the cases reached our center only after 12 hours. Similar delay seen in a review of 48 patients after bear attacks in Central India where $>90 \%$ cases reached tertiary center at $24-48$ hours of the event. ${ }^{5}$ However, in a review of pattern of bear maul maxillofacial injuries in Kashmir, they received all cases within 12 hours as all the encounters were in near vicinity of the hospital. ${ }^{4}$ Majority of the victims are male and of young age group with mean age of $37 \mathrm{yrs}$. This result is similar to the findings reported in studies from Kashmir, Central India, Canada and Alaska. ${ }^{4-8}$ This can be explained on the basis of more outdoor activity of males and youths in our society than females and elderly. Especially while visits to forest to collect firewood.

We found a wide distribution of the encounters in the country as it a landscape full of forest in the plains (Terai) in the south, hills in the middle and mountains in the north of the country. Brown sloth bear seem to habitat the southern Terai belt where as more number of the Himalayan black bear encounters are seen in the hills and the northern mountains. ${ }^{9}$ As per the habitat of the bear, all the attacks were by sloth bears in Nagpur and by black bear in the Himalayan ranges. ${ }^{5,4}$ In contrast, bear mauls were more commonly by the grizzly in the west, as found in Alaska and Alberta. ${ }^{10,11}$

All victims were hemodynamically stable when received in ER and we had no mortalities in the study. This shows that attacks of the bear were not predatory but defensive/ sudden as found in $85 \%$ of cases in the study. The black and sloth bear are not as aggressive as their counterpart grizzly bear in the west. Comparable supportive findings are seen in study from Kashmir where all cases were stable in ER, $92.80 \%$ of attacks were a result of sudden encounters, $6.71 \%$ were provoked ones and $0.47 \%$ was from predatory encounters that lead to $2.39 \%$ mortality in 200 cases. $^{4}$ Similar findings of more stable patients and low mortality have been reported in other studies. ${ }^{5,12}$ A review of 500 black bear attacks reports only three fatalities. ${ }^{13}$ Contrary, higher mortalities were found in studies from Alaska and Alberta, showing that Grizzly attacks are much aggressive and prove to be fatal. ${ }^{7,8}$ Amongst the mortalities in Alaska, 28 were due to mauling by brown/grizzly bears compared to only three by the black bears. ${ }^{8}$ 
We found $94 \%$ of injuries were in the head and face region. Similar patterns of attack were seen in the study from Central India, where 46 out of 48 had facial or scalp injuries; $80 \%$ face and $54 \%$ head. ${ }^{5}$ In reports from Kashmir, face and jaws were affected in $97(80.57 \%)$, scalp in 228 $(54.67 \%)$ of the cases. ${ }^{4}$ Most of the case reports of bear maul injuries, as reported in the literature, belong to face and head only. ${ }^{14-17}$

Predominance of head and facial injuries in bear mauling can be explained on the basis that when bear attacks, they use their claws of forelimbs in standing position so as to have a high ground of attack. Sudden encounters are usually face to face, where humans are in erect position and being shorter than the bear in front of them, have their head and face in very vulnerable position to sustain a blow. So we can infer that it would be a good idea to lie down flat on the ground with both hand covering the head and face when encountered by a bear, to prevent the common facial injuries of bear maul.

Sixty percent of cases in the study sustained fractures of underlying bones that show the massive power of these blows. Similar findings seen in the study of bear mauling in Alaska where the author found fractures in $50 \%$ of cases. ${ }^{8}$ More than $50 \%$ of cases were associated with fractures in study reviewing case of bear maul in Central India and 45\% of which were zygoma fracture. ${ }^{5}$ Almost all the cases of fractures found in the study done in Garhwal, Himalayas involved facial skeleton. ${ }^{18}$ Study from Kashmir found bony injury (fracture and/or loss) in $31.41 \%$ cases and face was most commonly involved site of bony injuries (27.09\%). ${ }^{4}$

Eye was found to be the most common viscera injured in $59 \%$ of victim with permanent vision loss in four of them. This finding parallels the finding in study from Central India, where 14/48 cases of eye injuries with 4/48 blindness. Many more of case reports of bear maul to eyes can be seen in the literature. ${ }^{6,19,20}$ Targeted blows to eyes and face are probably because the bear attack its enemy in very venerable areas to weaken them with minimal effort so as to make them unable to see and bite.

Various types of injuries were encountered requiring the use of all the different steps of reconstructive ladder. We had more proportion $(10 / 17)$ of patient with the complex wounds requiring initial debridement followed by closure with graft, flap or free flaps than the simple wounds which were just debridement and closed with primary $(5 / 17)$ or secondary sutures $(2 / 17)$. In contrary reports from Central India, had more of the simple wounds that were sutured
(48) and only nine of them needed flap surgery. ${ }^{5}$ This could be because of the financial constrains of the patients in our population, that limited their asses to the tertiary center only for the wounds that could not be managed in the primary care center.

We had just three cases of wound dehiscence, two because of infection and one because of margin necrosis. One case of meningitis was due to and compound fracture of frontal bone with pneumocephalus who reached our hospital after 24 hours of the event. Every wound left a permanent scar but amongst the permanent damages were loss of vision in one eye in four cases, facial disfigurement in the form of contour deformities in six cases and ectropion in five cases.

Mean length of hospital stay was of 20 days in the initial treatment period similar to that seen in studies from Central India with 21 days and Canadian study with 22 days. ${ }^{5,11}$ Average number of operation undergone by the victims was two, similar to that found in other study. ${ }^{5}$ Study from the west reports three surgeries per case of bear maul injury. ${ }^{11}$ This is probably due to more complex injuries by grizzly bear and it also included subsequent scar revision procedures which are very unlikely in our part of the world where it may not be affordable by the patient and are of less priorities.

Eleven patients out of 17 patients did require subsequent surgeries/ procedures for deformity corrections but was unable to perform due to lost to follow up. One year follow up were only possible over the phone interviews to enquire about any problems they were having due to the consequences of the bear maul injuries and if they wanted any interventions for the complication they had. All patients had accepted the deformities well and didn't want any further intervention except one who is still in regular follow up and has undergone five corrective operations so far. This probably is due to social restrains of our low economic society.

\section{Conclusion}

The rising trend of grievous bear maul injuries are complex injuries requiring prompt multidisciplinary approach of management. Face and eyes are the most common sites of injuries and often associated with underlying fractures. Definitive single procedures are needed for patient in our part of the world where staged procedures requiring long term follow ups are not feasible. Bear maul though rarely fatal, leaves permanent disfigurement and disabilities. 


\section{References}

1. Shiva Sharma. Bear attacks 'on rise' in Annapurna area. Kantipur post,2014, 25-12.

2. Joshi AR, Garshelis DL, Smith LD. Home Ranges of Sloth Bears in Nepal: Implications for Conservation. Journal of Wildlife Management. 1995;59(2):204-214

3. Burton RG. A book of Man-eaters. 1931

4. Shah AA, Mir BA, Ahmad I et al. Pattern of bear maul maxillofacial injuries in Kashmir. Natl J Maxillofac Surg. 2010 Jul-Dec;1(2):96-101.

5. Patil SB, Mody NB, Kale SM et al. A review of 48 patients after bear attacks in Central India: Demographics, management and outcomes. Indian J Plast Surg. 2015 Jan-Apr;48(1):60-65.

6. Masoud T, Sajaad S, Lone IA et al. Pattern of ocular injuries following bear maul in Kashmir. Indian Journal of Medical Specialities, 2013 July - Dec; 4(2)

7. Tough SC, Butt JC. A review of fatal bear maulings in Alberta, Canada. Am J Forensic Med Pathol. $1993 ; 14: 22-7$.

8. Rose SE. Bear mauling in Alaska. Alaska Med. 1982;24:29-32.

9. Middaugh JP. Human injury from bear attacks in Alaska:1900-1985. Alaska Med. 1987;29:121-6.

10. Frank RC, Mahabir RC, Magi E et al. Bear maulings treated in Calgary, Alberta: Their management and sequelae. Can J Plast Surg. 2006;14:158-62.

11. Floyd T. Bear-inflicted human injury and fatality. Wilderness Environ Med. 1990;10:75-87.

12. Herrero S. Human injury inflicted by grizzly bears. Science. 1970;170:593-8.

13. Hayashi Y, Fujisawa H, Tohma Y et al. Penetrating head injury caused by bear claws: Case report. J Trauma. 2003;55:1178-80.

14. Kunimoto D, Rennie R, Citron DM et al. Bacteriology of a bear bite wound to a human: Case report. J Clin Microbiol. 2004;42:3374-6.
15. Vougiouklakis T. Fatal brown bear (Ursus Arctos) attack: Case report and literature review. Am J Forensic Med Pathol. 2006;27:266-7.

16. Jethani J, Nagori R, Ghodadara B. An unusual case of bear bite with severe loss of tissue. Indian J Ophthalmol. 2006;54:287-8.

17. Dwivedi S, Sood S, Mehrotra V et al. Injuries caused by the black Himalayan bear in the foothills of Garhwal, Himalayas. Trop Doct. 2003;33:115-7.

18. Roka YB, Roka N, Shrestha M et al. Penetrating head injury with bilateral eye avulsion due to Himalayan bear bite. Emerg Med Australas. 2012;24:677-9.

19. Venkataswami G, Rajagopalan AV. A case of injury of right eye by a bear. J All India Ophthalmol Soc. 1962;10:22-3. 